SAE paper 2008-01-1665. Copyright @ 2008 SAE International. This paper is posted on this site with permission from SAE International, and is for viewing only. Further use or distribution of this paper is not permitted without permission from SAE 


\title{
Experimental Investigation of Spark Assisted Auto-Ignition Combustion in a Small Two-Stroke Engine
}

\author{
Janitha Wijesinghe, Guang Hong \\ University of Technology Sydney (UTS), Australia
}

Copyright @ 2008 SAE International

\begin{abstract}
The local temperature of the in-cylinder mixture before combustion is critical to enable auto-ignition ( $\mathrm{Al}$ ) in a gasoline engine. Spark assistance is one of the methods to ensure the critical temperature required for autoignition. The application of the spark gives a time controlled initiation to the onset of ignition. In the work reported in this paper, spark assisted Al was experimentally investigated on a small two-stroke engine. The spark assistance and internal exhaust gas recirculation (EGR) were jointly applied to achieve and control Al. The results showed that at higher engine load, the onset timing of Al had a clear dependence on the timing of the spark and was consistent from cycle to cycle. At lower engine load, the assistance of the spark became necessary for keeping the $\mathrm{Al}$ operation to continue.
\end{abstract}

\section{INTRODUCTION}

Homogeneous charge compression ignition $(\mathrm{HCCl})$ is a novel combustion technology based on the principle of Al. It combines the benefits of the conventional spark ignition ( $\mathrm{SI}$ ) and compression ignition $(\mathrm{Cl})$ engines and has been regarded most promising for very low NOx and PM emissions and high thermal efficiency. However, some issues need to be addressed before $\mathrm{HCCl}$ is applied to engine products. Control of the onset of the Al is one of these issues.

The temperature of the homogenous charge before combustion is critical to enable $\mathrm{Al}$ in a $\mathrm{HCCl}$ engine. Internal exhaust gas recirculation (EGR), increasing compression ratio and pre-heating intake charge are typical techniques to attain the required $\mathrm{Al}$ temperature in a gasoline SI engine. However with these techniques, ignition timing and temperature of the mixture would vary from cycle to cycle as they are not controlled directly. Within this context use of spark ignition could be a possible option to achieve a more precise control of the timing.

To recover the indicative mean effective pressure (IMEP) lost by using EGR to raise the mixture temperature, a new combustion mode called spark- ignited compression ignition (SI-Cl) was claimed by Urushihara et al. [1]. In this $\mathrm{SI}-\mathrm{Cl}$, a small quantity of stratified mixture was ignited by a spark to raise the cylinder pressure and temperature for inducing $\mathrm{Cl}$ combustion. Experimental investigation of this concept was conducted on a medium-size 4-stroke singlecylinder engine with port and direct fuel injection. The results showed that the maximum IMEP was improved but the NOx was increased by the SI combustion.

In a research reported more recently [2, 3], Wang et al. investigated the effect of $\mathrm{SI}$ on $\mathrm{HCCl}$ combustion on a gasoline direct injection four-stroke engine. They had a focus on $\mathrm{HCCl}$ combustion at its critical status $(\mathrm{HCCl}-$ $\mathrm{CS}$ ). Their results showed that the stability of $\mathrm{HCCl}$ combustion at $\mathrm{HCCl}-\mathrm{CS}$ was improved by $\mathrm{SI}$ and that the transition fluctuations could be reduced by SI when the combustion mode was changed from $\mathrm{SI}$ to $\mathrm{HCCl}$. It also showed that the $\mathrm{SI}$ triggered global $\mathrm{HCCl}$ in the region misfiring occurred without the spark. It was concluded that the stable $\mathrm{HCCl}$ combustion was realized when the mixture temperature and concentration near the top dead center (TDC) exceeded HCCI-CS.

Compared with the work on $\mathrm{HCCl}$ on multiple-cylinder four-stroke gasoline engines, little research has been reported on $\mathrm{HCCl}$ on small two-stroke engines in the recent years, although first reported work on $\mathrm{HCCl}$ was associated with two-stroke engines [4]. Out of the recent work dealing with two stroke engines $\mathrm{Ma}$ et al. experimentally investigated on using auto-ignition on a small two-stroke engine with glow ignition [5]. Alternative fuels were used in this engine and their effect on combustion was investigated. In this work, the analyses of heat release and mass burned fraction calculated from the cylinder pressure were combined to determine the ignition timing and the polytropic index. Their results showed good correlations between these two methods.

In the work reported in this paper, the assistance of the spark plug was used to control the onset of $\mathrm{Al}$ in a small two-stroke engine. The aim of the paper is to analyze and discuss the effects of the spark assistance on the combustion characteristics of $\mathrm{Al}$ at the upper and lower load limits. 


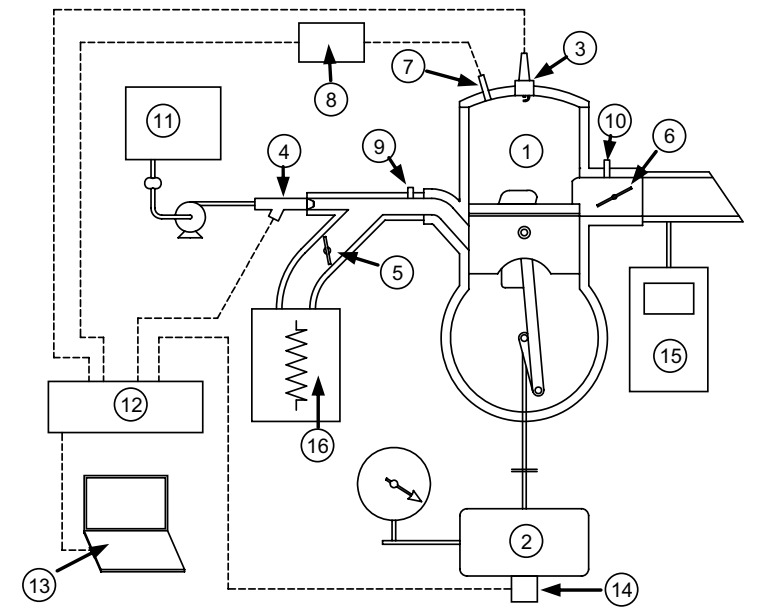

1-Test engine 2-Dynamometer 3-Spark plug 4-Fuel injector 5-Intake valve 6 -Exhaust valve 7 -Pressure transducer 8 -Charge amplifier 9Intake thermocouple 10-Exhaust thermocouple 11-Fuel supply system 12-Microcontroller 13-Data acquisition computer 14Incremental rotary encoder 15-Exhaust gas analyzer 16-Intake heater chamber

Figure 1: Experimental apparatus

\section{EXPERIMENTAL SETUP}

A $160 \mathrm{cc}$ piston ported single-cylinder two-stroke engine was used for this investigation. Its key specifications are listed in Table 1. Figure 1 is the schematic for the basic experimental apparatus used in the investigation.

Table 1: Engine specification

\begin{tabular}{|l|l|}
\hline Engine type & $\begin{array}{l}\text { Two-stroke; } \\
\text { Schnurle }\end{array}$ \\
\hline Bore & $61.5 \mathrm{~mm}$ \\
\hline Stroke & $56 \mathrm{~mm}$ \\
\hline No. of transfer ports & 2 \\
\hline Trapped compression ratio & $6.7: 1$ \\
\hline Exhaust port opening angle & $105.9^{\circ}$ ATDC \\
\hline $\begin{array}{l}\text { Transfer ports opening } \\
\text { angle }\end{array}$ & $117.8^{\circ}$ ATDC \\
\hline Fuel induction system & Intake pipe injection \\
\hline
\end{tabular}

A hydraulic dynamometer was used to measure the brake torque output of the engine. The cylinder pressure was measured using a $\mathrm{PCB} 112 \mathrm{~B}$ pressure transducer and a Kistler 504-E charge amplifier. The pressure data was acquired at every degree of crank rotation with a $\mathrm{NI}$ LabView data acquisition system. K-type thermocouples were used to measure the intake and the exhaust temperatures. An exhaust gas analyzer, Autodiagnostics, was used to measure the $\mathrm{HC}, \mathrm{CO}$, $\mathrm{CO}_{2}, \mathrm{NO}, \mathrm{O}_{2}$ and the air to fuel ratio (AFR).

To obtain a homogeneous air and fuel mixture inside the cylinder, gasoline fuel premixed with lubricant oil in a ratio of 40:1 was injected into the intake manifold using a low pressure fuel injector as shown in Figure 1. Fuel injection pressure was maintained at $300 \mathrm{kPa}$. The fuel injection was controlled using a PIC microcontroller shown by item 12 in Figure 1.

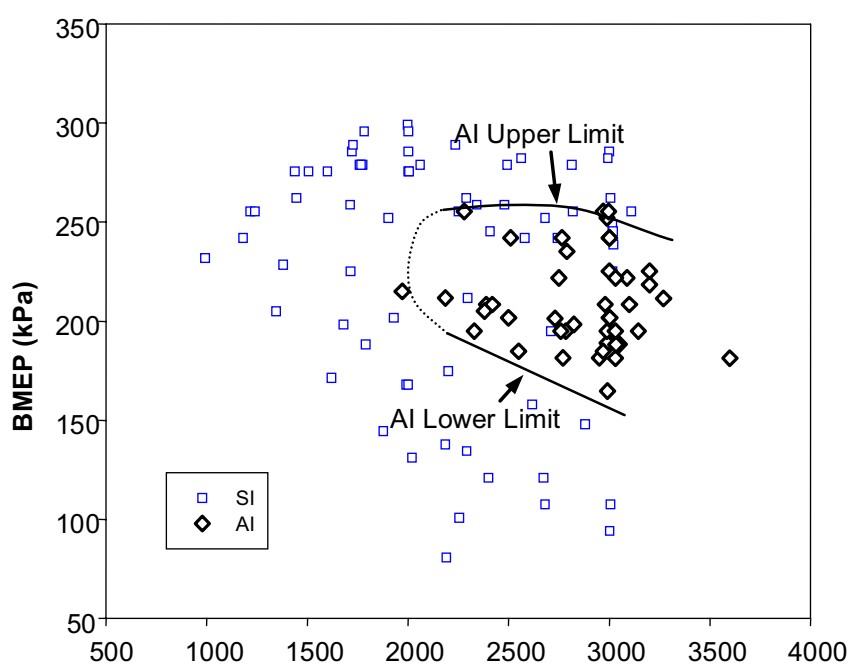

Engine Speed (RPM)

Figure 2: Engine operating regions for $\mathrm{Al}$ and $\mathrm{SI}$

An incremental rotary encoder with 360 pulses per revolution was used to determine the instantaneous angular position of the crankshaft. The output of the encoder was used as an external clock to drive the microcontroller which determined the SI timing, the fuel injection timing and the width of the fuel injection pulse.

\section{SPARK ASSISTED AUTO-IGNITION}

Previously the authors investigated the use of internal EGR to realize $\mathrm{Al}$ [9]. In their recent experimental investigation, the spark assistance and internal EGR were jointly applied to achieve and control Al. The percentage of the internal EGR was controlled using a butterfly valve mounted $20 \mathrm{~mm}$ downstream from the exhaust port. The exhaust valve was manually adjusted between $0^{\circ}$ and $60^{\circ}$, where $0^{\circ}$ indicated the fully-opened valve position and $60^{\circ}$ the fully-closed valve position. In our experiments, when the intake air was at room temperature, the exhaust butterfly valve angle was set to be in the range of $40^{\circ}$ to $55^{\circ}$ for the mixture with an airfuel ratio of $15-18$ to auto-ignite in the tested engine.

Figure 2 illustrates the engine operating regions for $\mathrm{SI}$ and $\mathrm{Al}$ achieved with internal EGR only, in terms of engine speed and the brake mean effective pressure (BMEP). The engine operating conditions with $\mathrm{Al}$ are denoted by ' $\nu$ ' and SI by ' $\square$ '. The SI data points were obtained in a condition with a stoichiometric air-fuel ratio and a fully opened exhaust valve. The Al data points were obtained in a condition with an air-fuel ratio of 16 and an exhaust valve angle of $50^{\circ}$.

As illustrated in Figure 2 the $\mathrm{Al}$ upper limit is defined as the maximum BMEP that could be reached in Al mode with the given exhaust valve restriction and air-fuel ratio. 
The Al lower limit is the misfire limit where the exhaust gas temperature was not high enough to promote continuous $\mathrm{Al}[6]$.

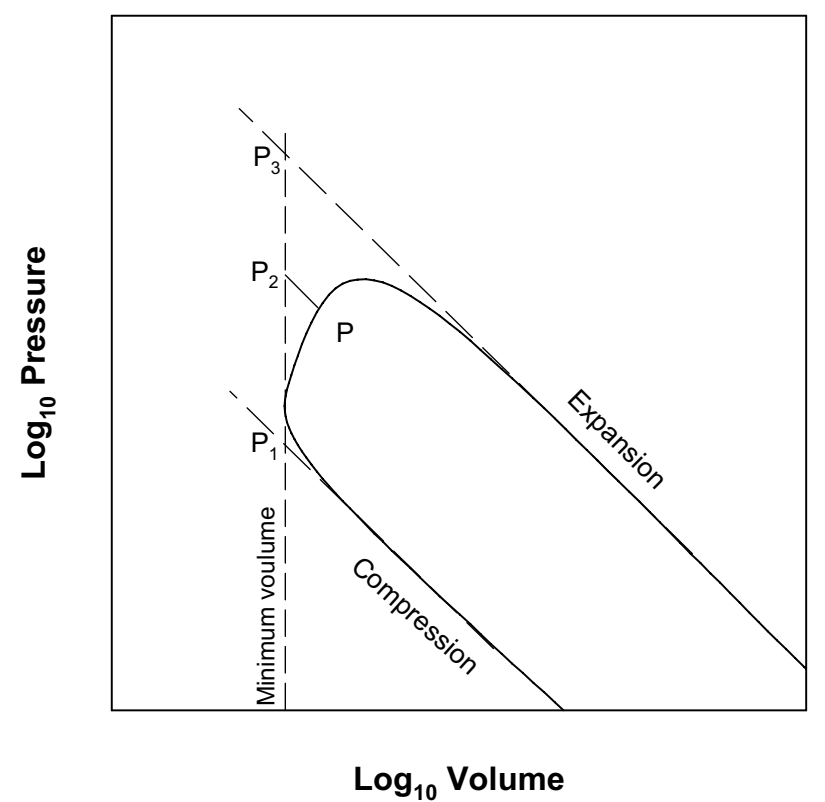

Figure 3: $\log _{10}$ Pressure vs. $\log _{10}$ Volume

The effect of the advanced spark on Al was tested under various engine load and speed conditions within the engine operating region as shown in Figure 2. For the results presented in this paper, the exhaust valve opening angle was $50^{\circ}$ and the air-fuel ratio was 16 . During the experiments, after the engine was operating with $\mathrm{Al}$, the engine was run for 15 to 20 minutes to allow it to reach a steady-state condition. The existence of the Al combustion under any operating condition was verified by disabling the spark.

The spark timing was controlled using a PIC micro controller, item 12 in Figure 1, during the engine operation. The default firing angle was defined as $20^{\circ}$ according to the manufacturer's specification. Before the engine started for spark assisted Al operation, the spark timing was set manually.

\section{RESULTS AND DISCUSSION}

Results of two cases, in the upper and the lower limits of Al operating conditions, will be analyzed and discussed. For each case the effect of spark assistance on Al will be investigated by analyzing the cylinder pressure data and the mass burned fraction.

\section{MASS BURNED FRACTION}

In order to determine the occurrence or the onset of $\mathrm{Al}$, mass burned fraction (MBF) was calculated using the cylinder pressure. The method used to calculate the MBF was first introduced by Marvin as described in [7]. The same method was explained in more detail by Ivansson in [8]. If the mass inside the cylinder is assumed to be compressed and expanded polytropically, the compression and expansion processes in a cycle could be described by straight lines on a Log Pressure vs. Log Volume diagram as shown in Figure 3.

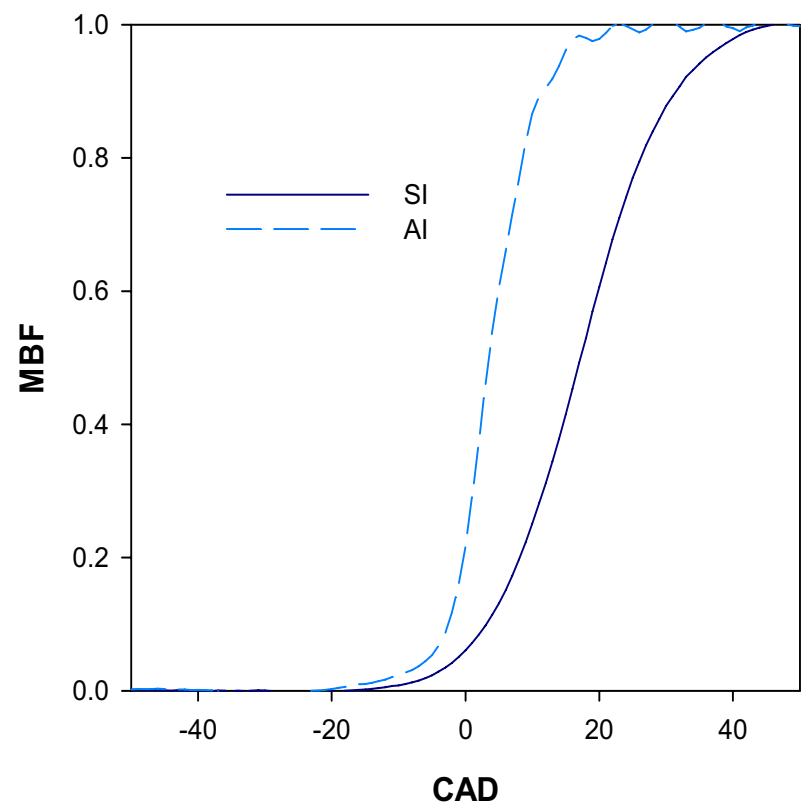

Figure 4: Comparison of mass burned fractions in SI and $\mathrm{Al}$ combustion

In Figure 3, $P_{1}$ and $P_{3}$ are the points where the extended compression and expansion lines intersect the minimum volume line. $P$ represents the instantaneous pressure of a point of interest. Point $P_{2}$ is the projection of $P$ on the minimum volume line, defined by Equation 1.

$$
P_{2}=P\left(\frac{V}{V_{c}}\right)^{n}
$$

Where $\mathrm{V}$ is the instantaneous cylinder volume, $\mathrm{V}_{\mathrm{C}}$ is minimum volume or the clearance volume of the cylinder and $n$ is the polytropic index. Now the MBF at a point of interest such as $\mathrm{P}$ can be calculated using Equation 2.

$$
\mathrm{MBF}_{\mathrm{P}}=\frac{\mathrm{P}_{2}-\mathrm{P}_{3}}{\mathrm{P}_{1}-\mathrm{P}_{3}}
$$

\section{IDENTIFICATION OF AI}

When the engine was operating on $\mathrm{Al}$, the mode of ignition was easily confirmed by disabling the spark. However while the spark assistance was in use it was important to verify whether the combustion of the mixture was in the mode of auto-ignition or spark ignition. As the combustion is spontaneous in the $\mathrm{Al}$ mode, the combustion is faster and the mass burnt fraction is distinguishably higher than that in $\mathrm{SI}$ combustion. To identify the Al, the $10 \%-90 \% \mathrm{MBF}$ duration was considered. Figure 4 shows the mass burned fraction curves for a typical SI combustion and AI 
combustion. As shown in Figure 4, for SI combustion, $10 \%-90 \%$ MBF duration is $30^{\circ}$. However in the Al combustion event the $10 \%-90 \%$ MBF duration is only $10^{\circ}$. As such, the short duration of the heat release verified that the mode of combustion was Al during the experiments.

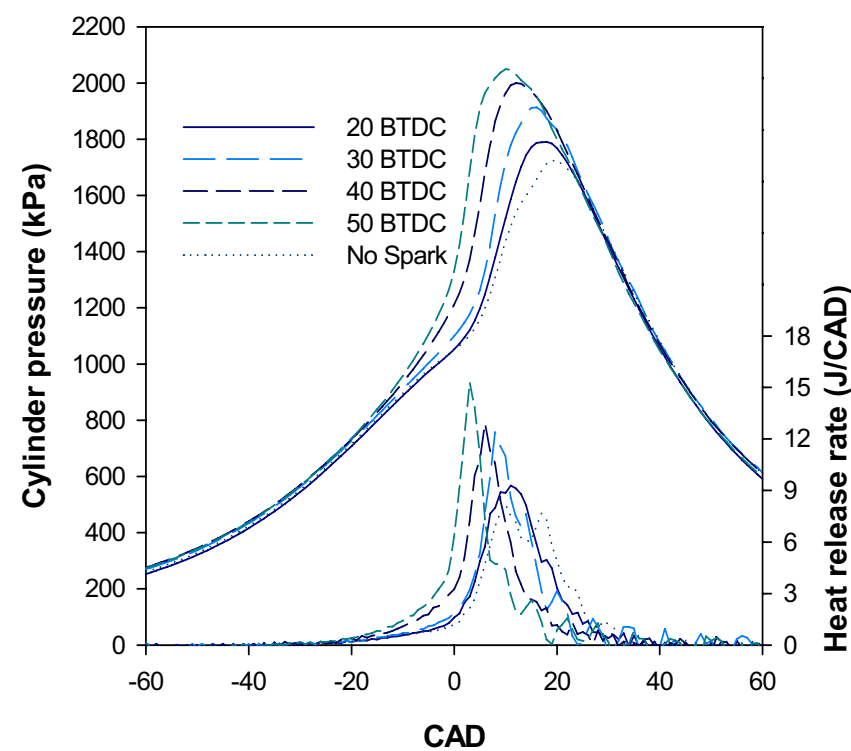

Figure 5: Cylinder pressure distributions and HRR with and without spark assistance at Al upper limit

\section{EFFECTS OF SPARK ASSISTANCE AT AI UPPER LIMIT}

Figure 5 illustrates the cylinder pressures and heat release rates (HRR) with and without spark assistance in one engine operating condition at the upper load limit of Al. The engine speed was $2900 \mathrm{rpm}$ and the IMEP was $320 \mathrm{kPa}$. The SI timing angles were $20^{\circ}, 30^{\circ}, 40^{\circ}$ and $50^{\circ}$ before top dead centre (BTDC). At this load speed setting when the exhaust temperature became stabilized around $360^{\circ} \mathrm{C}$, the engine was able to run in $\mathrm{Al}$ mode continuously without the spark assistance. However as described in [9] Al operation without the spark assistance was characterized by high audible noise and non uniform peak pressure. In Figure 5 the Al operation without the spark assistance is termed as 'No Spark'.

As shown in Figure 5 the onset of ignition and the peak cylinder pressure are significantly influenced by the timing of the spark. When the spark is advanced from $20^{\circ}$ to $50^{\circ} \mathrm{BTDC}$, the occurrence of the combustion peak pressure is advanced. The peak pressure value is also increased from $1800 \mathrm{kPa}$ to $2050 \mathrm{kPa}$. At the Al upper limit, the internal EGR is sufficiently hot to initiate the Al without the assistance of the spark. As shown in Figure 5 , without spark assistance, the onset of the autoignition occurs after the TDC and the peak pressure even later in the expansion stroke. When the spark is advanced the onset of the ignition is also advanced and the cylinder peak pressure is shifted towards the top dead center. As a result, the expansion work is increased. Further from the heat release rate distribution shown in Figure 5 it can be observed that the maximum rate of heat release has increased with the advancing spark timing.

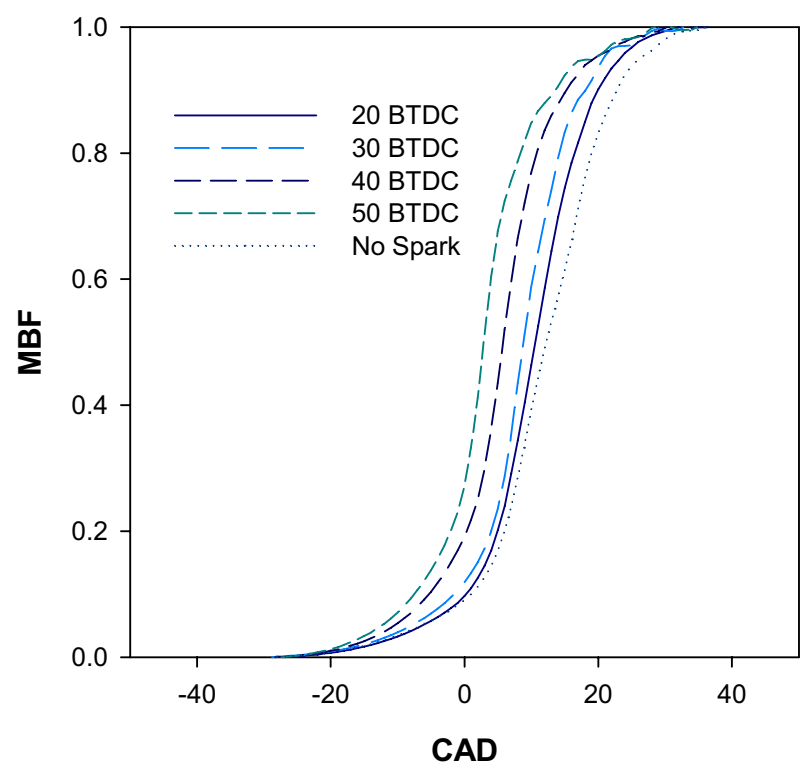

Figure 6: Mass burned fractions with and without spark assistance at Al upper limit

Figure 6 depicts the MBF varying with the crank angles corresponding to the results shown in Figure 5 . The $10 \%$ MBF angle, $50 \%$ MBF angle and 10\% - 90\% MBF angle for these conditions are given in Table 2. As shown in Table 2, all five results shown in Figure 6 have approximately the same $10 \%-90 \%$ burn duration, although the phases are different. Therefore, it could be inferred that the duration of the main combustion period during $\mathrm{Al}$ is not affected by the SI timing.

Table 2: MBF values in various phases

\begin{tabular}{|c|c|c|c|c|c|}
\hline & \multirow{2}{*}{ No Spark } & \multicolumn{4}{|c|}{ Spark timing } \\
\cline { 3 - 6 } & & 20 BTDC & 30 BTDC & 40 BTDC & 50 BTDC \\
\hline $10 \%$ angle ATDC & 2 & 0 & -2 & -5 & -7 \\
$50 \%$ angle ATDC & 12 & 11 & 9 & 6 & 3 \\
$10 \%-90 \%$ angle & 21 & 20 & 20 & 20 & 21 \\
\hline
\end{tabular}

When the engine was running without the spark assistance the standard deviation of the $10 \%$ burn angle for consecutive 15 engine cycles was $1.7^{0}$. When the spark assistance was turned on and the spark timing was set to $50^{\circ}$ BTDC, this standard deviation became to be $1.4^{0}$. Thus the spark assistance in this case has resulted in a slight improvement in the variation of the ignition timing.

Table 3: Burned angles of 'No-Spark' operation

\begin{tabular}{|l|cccccccccc|}
\hline & 1 & 2 & 3 & 4 & 5 & 6 & 7 & 8 & 9 & 10 \\
\hline $10 \%$ angle ATDC & 3 & 0 & 3 & -1 & 3 & -1 & 3 & 0 & 4 & 1 \\
$10 \%-90 \%$ angle & 21 & 16 & 24 & 18 & 24 & 15 & 21 & 16 & 22 & 17 \\
\hline
\end{tabular}

Table 3 shows the $10 \%$ MBF angle and the 10\%-90\% MBF angle of 10 consecutive cycles corresponding to 
'No Spark' operation given in Table 2. Even though its average was $2^{0}$ BTDC, the $10 \%$ burned angle was increasing and decreasing alternately from cycle to cycle as shown in Table 3. This may be because that the early igniting cycles had shorter combustion durations while the late igniting cycles had longer combustion durations. Ishibashi et al described a similar form of combustion at the higher load zone which they phrased as 'Two-stage SI combustion' [10]. As indicated in [10], an early ignited cycle with a shorter combustion duration results in a lower temperature in the exhaust gas. This causes the ignition in the following cycle to occur later with a longer combustion duration. The cycle with a longer combustion duration, on the other hand, results in a higher temperature in the exhaust gas, followed by a shorter combustion period in the next cycle. This may explain how the cycle-to-cycle alternating pattern shown in Table 3 was formed when the engine was operated on Al without the spark. Based on the above phenomenon it could also be inferred that the temperature of the residual gas would be varying from cycle to cycle.

The cycle-to-cycle alternation of the ignition timing and the combustion duration was not evident in the cycles with spark assistance at $50^{\circ}$ BTDC. The existence of the spark gives a time controlled initiation to the onset of ignition. In this case the onset of the ignition depends more on the local high temperature caused by the spark than on the overall temperature of the residual gas and the fresh charge mixture. Thus spark timing at a much earlier stage of the compression stroke reduces the cyclic variability of the onset of $\mathrm{Al}$ at the upper load limit.

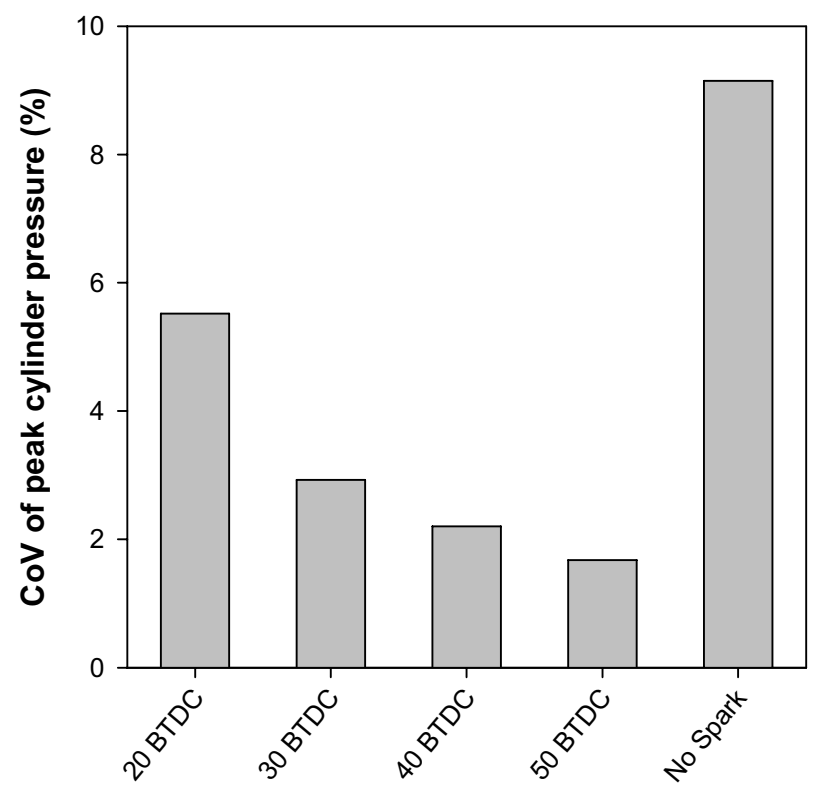

Figure 7: Coefficient of variation of the peak cylinder pressure at the Al upper limit

Another significant impact of the spark ignition timing on the upper load operation can be seen in Figure 7. When the engine was operating without the spark assistance the coefficient of variation (CoV) of the peak cylinder pressure was $9 \%$. Once the spark assistance is turned on with the firing angle at its default value of $20^{\circ}$ BTDC, the $\mathrm{CoV}$ reduced to $5.5 \%$. Figure 7 also shows that the $\mathrm{CoV}$ was reducing with the increase of the advanced spark timing.

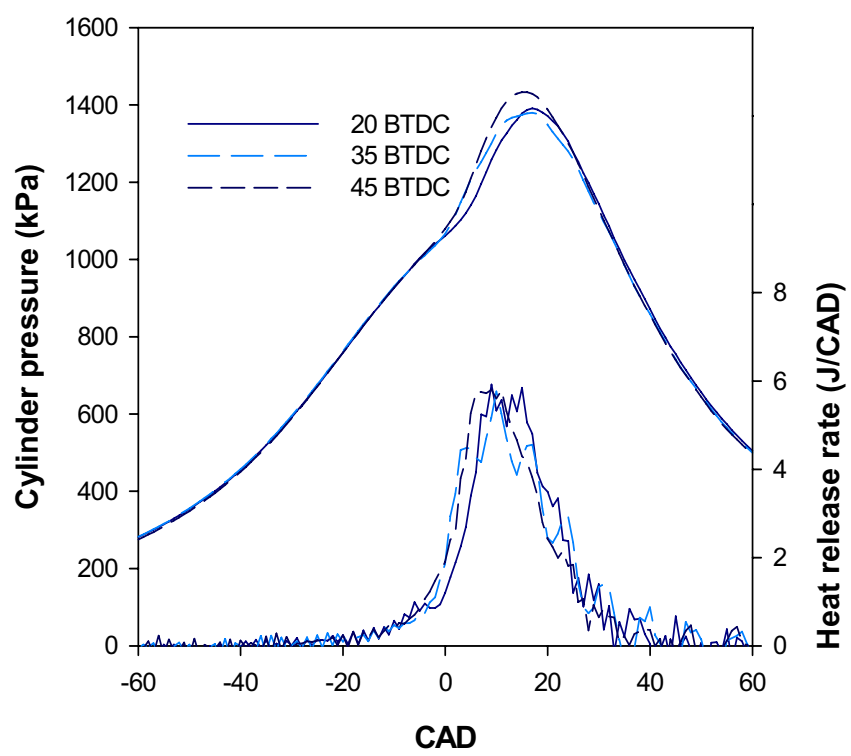

Figure 8: Cylinder pressure distribution and HRR with spark assistance at Al lower limit

The reason for the higher $\mathrm{CoV}$ for the $\mathrm{Al}$ operation without the spark assistance can be explained by the fact that the temperature of the residual gas varies from cycle to cycle. When the spark assistance is turned on, the local high temperature caused by the heat release from the spark plug gives a consistent initiation for the rest of the mixture to auto-ignite at an earlier timing in contrast to the temperature rise given by internal EGR at a later timing.

\section{EFFECTS OF SPARK ASSISTANCE AT LOWER LIMIT}

The Al lower limit was achieved by partially closing the intake valve and reducing the dynamometer load just above the misfiring limit of the engine. Figure 8 illustrates the cylinder pressure distribution and the corresponding heat release rate for three spark ignition timings during the lower load operation. The SI timing angles were $20^{\circ}, 35^{\circ}$ and $45^{\circ}$ BTDC. The engine was operated at a nominal speed of $3000 \mathrm{rpm}$ and an IMEP of $175 \mathrm{kPa}$. The maximum exhaust temperature was $340^{\circ} \mathrm{C}$.

At the load setting corresponding to Figure 8, when the spark plug was disabled the Al mode could not be sustained for a long period. Due to the typical misfiring nature at lower loads one incomplete combustion cycle could lead to an immediate drop of exhaust temperature, making it impossible for Al to occur in the next cycle. Therefore the assistance of the spark plug was critical for the continuation of Al. 
As shown in Figure 8, when the spark ignition timing was advanced up to $45^{\circ}$ BTDC there was a slight increase in the combustion peak pressure compared to the other two firing angles. Apart from this variation, SI timing did not appear to have a significant effect on the in-cylinder pressure during combustion. Figure 8 also indicates that the heat release rates for the three spark ignition timings do not vary significantly from one to the other.

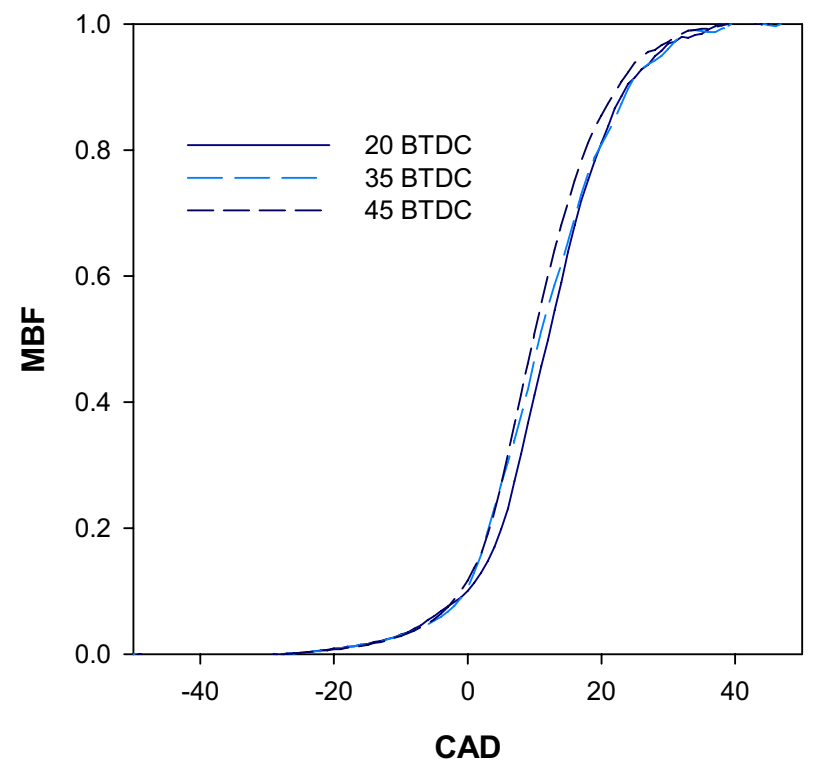

Figure 9: Mass burned fractions with spark assistance at $\mathrm{Al}$ lower limit

Figure 9 illustrates the corresponding burned mass fraction during the experiments given in Figure 8. According to Figure 9 , the $50 \%$ of the MBF for the $45^{\circ}$ spark ignition timing occurred approximately $2^{\circ}$ earlier than that for $20^{\circ}$ spark ignition timing. The results presented in Figure 9 shows that at the lower load region the onset of auto-ignition is not strongly influenced by the spark ignition timing. The reason for this has not been clearly explained in the literature. However it is likely that the heat added by the spark around its vicinity is just sufficient to initiate the low temperature reactions. The subsequent main heat release would take place more or less at a constant timing when the in-cylinder temperature is raised at the end of compression, irrespective of the spark ignition timing.

The cyclic stability of the lower load operation was not satisfactory compared to that of the upper load limit operation. The poor cyclic stability was evident from the high variation of the peak cylinder pressure. Figure 10 illustrates the CoV of the peak cylinder pressure when the engine was operating at $\mathrm{Al}$ lower load limit with spark ignition timings at $20^{\circ}, 35^{\circ}$ and $45^{\circ}$ BTDC. As it was presented earlier the existence of the spark was absolutely necessary for the continuous operation of the engine. Even though the engine continued to run with the assistance of the spark, the cylinder pressure traces showed that there was a high degree of cycle-to-cycle variations in the peak pressure. As presented in Figure
10 the CoV for the spark ignition timings of $20^{\circ}, 35^{\circ}$ and $45^{\circ}$ BTDC were $13 \%, 17 \%$ and $15 \%$ respectively. In contrast to these results, for the upper load limit case, the highest CoV was only $9 \%$. Furthermore these results indicate that there is no clear trend of improvement in the cycle-to-cycle variations with the advanced spark ignition timing.

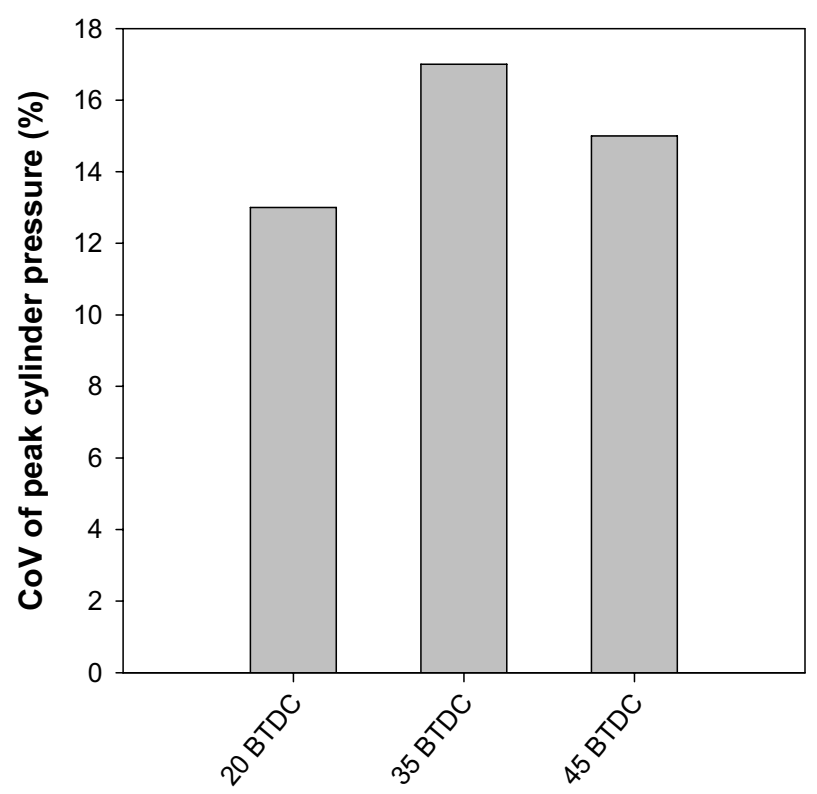

Figure 10: Coefficient of variation of the peak cylinder pressure at the Al lower limit

Compared to upper loads the heat added during combustion at lower loads is relatively small. Therefore at lower load conditions the temperature of the residual gases trapped inside the cylinder may not be high enough to result in $\mathrm{Al}$ without the assistance of the spark. Furthermore, the random nature of the fresh charge concentration, especially near the spark plug, affects the amount of heat added to its surrounding. If the fresh charge zone was large enough around the vicinity of the spark then it is possible that the entire contents of the cylinder would auto-ignite, leading to a more completely burnt cycle and a representative high peak pressure. On the other hand if the fresh charge zone was smaller, the fresh charge may not completely burn. Thus the resulting peak pressure would be lower. As such a significant variation of peak cylinder pressure could be caused. In other words the relatively high CoV is due to a combination of several factors including low temperature of residuals and the randomness of the mixture formation prior to combustion.

\section{CONCLUSIONS}

An electric spark was used with the aim of assisting $\mathrm{Al}$ in a small two-stroke engine. The effect of the spark assistance on Al was experimentally investigated. The outcomes of this investigation are concluded as follows.

1. At the Al upper limit, the spark timing had a significant effect on the ignition timing and the peak 
cylinder pressure. The timing of the ignition, i.e. the onset of the $\mathrm{Al}$, was advanced with the advanced spark. The peak cylinder pressure increased and its occurrence was advanced with the advanced spark.

2. At the upper load limit Al combustion demonstrated an alternating pattern of ignition timing and combustion duration. The spark assistance was able to reduce this alternating nature.

3. Near the lower load limit of the engine operating conditions with $\mathrm{Al}$, the assistance of the spark became necessary for keeping the Al operation to continue.

4. SI timing had little effect on the Al timing at lower load operating conditions, compared to that of upper loads.

5. The stability of the Al combustion was not satisfactory even with the spark assistance, when the engine was running at lower load.

\section{ACKNOWLEDGMENTS}

The authors are grateful to Mr. Matthew Low, Mr. Richard Dibbs and Mr. Mark Benjamin for their support in preparing the experiments and the electronic circuits for fuel injection control.

\section{REFERENCES}

1. Urushihara, T., Yamaguchi, K., Yoshizawa, K. and Itoh, T., A study of a gasoline-fueled compression ignition engine. Expansion of $\mathrm{HCCl}$ operation range using SI combustion as a trigger of compression ignition, SAE paper 2005-01-0180, 2005.

2. Wang, Z., Wang, J., Shuai, S., Tian, G., An, X. and $\mathrm{Ma}, \mathrm{Q}$. Study of the effect of spark ignition on gasoline $\mathrm{HCCl}$ combustion. Proceedings of IMechE, Part D: Journal of Automobile Engineering, Vol. 220, pp 817- 825, 2006.

3. Wang, Z., Wang, J., Shuai, S and Ma, Q. New gasoline homogeneous charge compression ignition combustion system using two-state direct injection and assisted spark ignition. Proceedings of IMechE, Part D: Journal of Automobile Engineering, Vol. 220, pp 367- 378, 2006.

4. Onishi, S., Jo, S., Shoda, K., Jo, P. and Kato, S. Active thermo-atmosphere combustion (ATAC) - A new combustion process for internal combustion engines. SAE paper 790501, 1979.

5. Ma, H., Kar, K., Stone, R., Raine R. and Thorwarth, $H$. Analysis of Combustion in a small homogeneous charge compression assisted ignition engine. International Journal of Engine Research, Vol. 7, No. 3, pp 237-253, 2006.

6. Zhao, H., Li, J., Ma, T. and Ladommatos, N. Performance and Analysis of a 4-Stroke Multi-
Cylinder Gasoline Engine with CAI Combustion. SAE Paper 2002-01-0420, 2002.

7. Marvin, C. F. Combustion time in the engine cylinder and its effects on engine performance. NACA Tech Report 276, 1927.

8. Ivansson, N. Estimation of the Residual Gas Fraction in an $\mathrm{HCCl}$-engine using Cylinder Pressure. Undergraduate Thesis, Linkoping University, Sweden, 2003.

9. Wijesinghe, J. and Hong, G. Using auto-ignition to improve the cycle-to-cycle variations of a small twostroke engine. SAE Paper 2007-32-0040, 2007.

10. Ishibashi, Y. and Asai, M. Improving the exhaust emissions of two-stroke engines by applying the activated radical combustion. SAE Paper 960742, 1996.

\section{CONTACT}

Janitha Wijesinghe

Research Student in Mechanical Engineering

Faculty of Engineering

University of Technology Sydney

PO Box 123, Broadway, NSW 2007,

Australia

Email: Janitha.Wijesinghe@eng.uts.edu.au 